\title{
Resistant gastric environment of Lactobacillus crispatus from stomach inhibits Helicobacter pylori colonization and attenuates gastric inflammation
}

\section{Ning Wang}

West China biopharm research institute, West China hospital, Sichuan University, Chengdu,China

\section{Fang-yuan Mao}

College of pharmacy, Army Medical University

\section{Wei-wei Huang}

Department of Pathogen Biology, College of Basic Medicine, Chongqing Medical University, Chongqing, China

\section{Hui Kong}

Department of Microbiology and Biochemical Pharmacy, College of Pharmacy, Army Medical University, Chongqing, China

\section{Yun Shi}

West China biopharm research institute, West China hospital, Sichuan University, Chengdu,China

\section{Zhi-bang Yang}

Department of Pathogen Biology, College of Basic Medicine, Chongqing Medical University, Chongqing, China

\section{Quan-ming Zou}

Department of Microbiology and Biochemical Pharmacy, College of Pharmacy, Army Medical University, Chongqing, China

\section{Yan Li}

West China biopharm research institute, West China hospital, Sichuan University, Chengdu,China

\section{Gang Guo ( $\sim$ 1078748333@qq.com )}

Department of Microbiology and Biochemical Pharmacy, College of Pharmacy, Army Medical University, Chongqing, China

\section{Research article}

Keywords: H. pylori, Gastric inflammation, Gnotobiotic, Lactobacillus, Gastric environment

Posted Date: May 21st, 2019

DOI: https://doi.org/10.21203/rs.2.9712/v1 
License: (c) (i) This work is licensed under a Creative Commons Attribution 4.0 International License. Read Full License 


\section{Abstract}

Background Recent studies have shown that gastric-derived Lactobacillus can inhibit the colonization of $\mathrm{H}$. pylori and attenuate gastric inflammation in conventional animals, but the resistant of Lactobacillus to gastric environment is still unknown. Here, we aimed to screen the candidate Lactobacillus that could adapt to the harsh gastric environment and inhibit the colonization of H. pylori. Results In vitro, the growth rate of seven Lactobacillus strains in different $\mathrm{pH}$ and bile salt concentration were tested, the size of inhibition zone and adhesion rate of $\mathrm{H}$. pylori when Lactobacillus exist were measured. In gnotobiotic mice models, we examined the amount of colonization of L. crispatus and H. pylori by qRT-PCR and evaluated the inflammation in the gastric tissue by the content of MPO and H\&E stain. In vitro experiments showed L. crispatus had a better growth rate than other six Lactobacilluses in $\mathrm{pH} 2.5$ to 4.5; under the $0.2 \%$ bile salt concentration, other bacteria did not grow except for L. crispatus; L. crispatus yielded $24.2 \mathrm{~mm}$ of mean inhibitory zone diameters; the adhesion rate of $\mathrm{H}$. pylori only reached $41.3 \%$ in H. pylori-L. crispatus group(HLG). In vivo, the amount of colonization of H. pylori in HLG is fifteen times less than that in $\mathrm{H}$. pylori group $(\mathrm{HG})(\mathrm{p}<0.05)$; the MPO value of HG was 1.4 times that of HLG; the gastric tissue inflammation of HLG was obviously lighter than HG. L. crispatus may be an adjunctive therapy for treating H. pylori- associated disease in clinic. Conclusions L. crispatus has resistance to low acid and high bile salts environment and it inhibits the growth of $\mathrm{H}$. pylori and the subsequent inflammation H. pylori caused in gnotobiotic Kunming mice model, which suggest the potential of developing L. crispatus as clinical agents.

\section{Background}

Helicobacter pylori(H. pylori) is a pathogen, which may cause chronic gastritis, peptic ulcers, gastric adenocarcinoma, and gastric mucosa-associated lymphoid tissue lymphoma [1, 2]. H. pylori infection has a general prevalence from $11 \%$ in industrialized countries to $95 \%$ in developing countries [3]. Several strategies have been proposed to eradicate H. pylori, including the standard first-line treatment (such as proton pump inhibitors, two antibiotics), quadruple, sequential, and concomitant treatments [ 4 ]. However, the eradication rates for $\mathrm{H}$. pylori infection have decreased to less than $80 \%$ in many countries [ 5 ], and the antibiotic resistance have become more serious [ 6 ]. Therefore, alternative treatments are of interest.

Microecology theory provide an excited idea to resist the infection of $\mathrm{H}$. pylori [ 7]. Lactobacilli are one of human gastric microbiota, and can adhere to the stomach wall and grow under harsh acidic conditions[ 8], theyare also probiotics that have positive effects for the health of humans and animals [ 9]. It has been reported that Lactobacillus can inhibit the adhesion and growth of $H$. pylori in in vivo studies [ 10,11$]$. In Mongolian gerbils model, Lactobacillus have an anti-infective effect against $H$. pylori [ 12]. According to Thiraworawong's reports, Gastric-derived L. plantarum XB7 can modulate gastric mucosal inflammation in Sprague-Dawley rat model [13]. In some reports, Lactobacillus ingestion could even decrease the risk of some cancer and tumors [14,15]. Meanwhile, Lactobacillus adjunct therapy have the potential to reduce severity of side effects related to $H$. pylori eradication therapy [13], increase the H. pylori eradication rate [16], and decrease the severity of host cell damage [17]. So Lactobacillus will be a 
promising microbial ecological agent that functions as an adjunctive therapy for treating H. pyloriassociated disease.

The stomach is a harsh environment, its $\mathrm{pH}$ is usually around 3.0 and the bile salt concentration is $0.03 \%$ to $0.3 \%$ [ 18]. Lactobacillus can colonize and live in the stomach which depend mainly on its acid and bile salt resistant [ 19,20], acid and bile salt resistance are also important indicators for screening Lactobacillus as probiotics [21]. Although some studies have shown that Lactobacillus can inhibit the $H$. pylori growth and reduce inflammation, but they did not study the acid and bile salt resistant of Lactobacillus, which will be affected in further development of Lactobacillus as probiotics to play against H. pylori in human gastric.

In the present study, we chose six Lactobacillus strains from the stomach of 21 healthy person, and examined the ability of acid and bile salt resistant, the size of inhibition zone and the adhesion rate of $H$. pylori in vitro. Based on above results, the most promising candidate L. crispatus was chosen. We use the L. crispatus and $H$. pylori successfully constructed the model of mono- and di-associated gnotobiotic Kunming mice models. Meanwhile, the amount of bacteria in stomach were detected, the degree of gastric mucosal inflammation were evaluated by the content of MPO in stomach tissue and the HE staining of gastric biopsy.

\section{Results}

\section{Acid and bile salt resistance of Lactobacillus}

After four hours incubation, the growths of all the Lactobacillus strains were shown in Fig. 1. The net growth of L. crispatus reached more $170 \%$ at $\mathrm{pH} 2.5$ and 3.0, the value of the L. crispatus were 1.5 times that of the $\mathrm{L} 2(p=0.002,0.000)$, meanwhile other strains were subject to different degrees of growth inhibition. At pH 4.0 and pH 4.5, L. crispatus also grow better than other strains, but the growth advantage was not obvious compared with $\mathrm{pH} 2.5$ and 3.0. In general, L. crispatus has a stable resistance to acid under low $\mathrm{pH}$ relative to other strains.

In Fig. 2, growth rate of all strains fell with the increase of concentration of bile salts. At the bile salt concentration $0.2 \%$, only $L$. crispatus were in growth, other strains' germination was stopped. When the concentration of bile salt is $0.1 \%$, L. crispatus were grown better than other strains $(p<0.05)$, the net growth is $100 \%$. The L6 and L7 did not grow at the concentration of bile salt $0.05-0.2 \%$. According to the above results, $L$. crispatus also has better bile salt tolerance than other six strains.

\section{Lactobacillus inhibit the growth and adhesion of $H$. pylori in vitro}


As shown in Table 1, all the Lactobacillus have a inhibitory effect on the growth of $H$. pylori by Oxford cup method in vitro, but there is a best effect that L. crispatus inhibited the growth of the H. pylori, the value of inhibition zone is $24.2 \mathrm{~mm}$, which is 1.8 fold that of $L 2(p=0.000)$, and 3.2 fold that of $L 7(p=0.000)$. There were statistically significant differences in the L3 compared with other strains at IZD $(p=0.000)$.

With the H. pyloris adhesion rate as the positive control, the adhesion rate is defined as $100 \%$. In the interaction between $\mathrm{H}$. pylori and Lactobacillus, all the Lactobacillus have a inhibitory effect on the adhesion of $H$. pylori to GES, at the same time, the adhesion rate of $H$. pylori in L-H group are higher than that in $\mathrm{H}-\mathrm{L}$ group for all Lactobacillus (Table 2). In L-H and $\mathrm{H}-\mathrm{L}$ group, the adhesion rate of $H$. pylori when L3 exsited are $51.2 \%$ and $41.3 \%$, the adhesion rate of $H$. pylori are $10 \%$ lower than other groups $(p=$ 0.000). In turn, the inhibition of H. pylori adhesion of $\mathrm{L} 3$ is strongest.

\section{The quantitative of $H$. pylori and L. crispatus in stomach}

The colonization amount of H. pylori and L. crispatus in different gnotobiotic Kunming mice is shown in Table 3. The colonization amount of $H$. pylori in HG is $2.008 \times 10^{7} \mathrm{copies} / \mathrm{g}$, it is 5.2 times that of LHG and 14.8 times that of HLG, there were statistically significant differences between them $(p=0.000$, 0.000). At the same time, the amount of L. crispatus in LHG and HLG are more than $1.0 \times 10^{6} \mathrm{copies} / \mathrm{g}$. It shows that $L$. crispatus can suppresse the adhesion and colonization of $H$. pylori in vivo, the L. crispatus has more obvious inhibitory effect among orally administered $L$. crispatus after $H$. pylori infection, which is consistent with the results of adhesion experimental in vitro.

\section{Evaluation of gastric inflammation}

To estimate the degree of inflammation, the MPO experiment data of four groups are shown in Fig. 3. In each groups, the value of MPO is relatively concentrated, this suggests that the experiment has good uniformity. In HG, the value of MPO is $0.248 \mu \mathrm{g} / \mathrm{g}$, and the HLG is only $0.173 \mu \mathrm{g} / \mathrm{g}$, the $\mathrm{HG}$ is 1.2 and 1.4 times of LHG and HLG, separately $(p=0.003,0.000)$. It shows that $L$. crispatus obviously reduces the MPO level of gastric tissue and the degree of gastric tissue damage caused by MPO.

The gastric inflammation was also determined by the histopathological examination and histology scores. Histopathology in the LG was normal, there was moderate inflammation in the HG, while the LHG and HLG improved stomach inflammation (Figure 4). The histology scores for gastric inflammation are summarized in Table 4, the neutrophil and mononuclear cell infiltration was significantly increased in the HG when compared with the LHG and HLG $(1.25 \pm 015-16.46$ vs $0.50 \pm 0.53$ and $0.37 \pm 0.52, p=0.010,0.003$, respectively).

\section{Discussion}


Recent studies have revealed that Lactobacilli can inhibit the growth of $H$. pylori and reduce gastric inflammation, some of them are also derived human gastric, and these have been shown that Lactobacill will be a potential therapeutic agent for treating the infection of $H$. pylori. However, it has not been clairified that whether these strains can colonize the human stomach and survival. In this study, we examined the acid and bile salt resistance of seven Lactobacilli strains in vitro, however, only L. crispatus has a best acid and bile salt resistance. We then studied the growth and adhesion rate of $H$. pylori that inhibited by the seven Lactobacilli strains, all these strains have a resistance to $H$. pylori activity, but the activity of $L$. crispatus is outstanding. Combined with the above results, we further confirmed the antigrowth and anti-inflammatory properties of L. crispatus in the gnotobiotic Kunming mice models, the effect of anti-growth is consistent with the experimental results in vitro, furthermore, it significantly reduce the $H$. pylori-associated gastritis at the same time. These data strongly suggest $L$. crispatus will be a probiotics agent that can prevent the infection and improve the inflammation of $H$. pylori in human stomach.

Lactobacillus secretes some antibacterial metabolic products, such as lactic acid, bacteriocin, peroxide, proteinase, exopolysaccharide[22], lactic acid inhibits the urease activity and viability of $H$. pylori among these. According to Sunanliganon's report [10], low pH values are important for anti-H. pylori activity. At the same time, $H$. pylori infection and the subsequent increase of gastric $\mathrm{pH}$ value may result in a more permissive milieu for colonization with other bacteria, that their metabolic products associated with stomach related diseases[23]. In this study, the acid-resisting strain also produced a large amount of acid (data not shown), which is also very important that to maintain the normal environment of stomach and resist the $H$. pylori infection.

To make Lactobacillus inhabit the complex and changeable stomach and play the role of probiotics to maintain the normal $\mathrm{pH}$ and bacteria flora of stomach, acid and bile tolerance of its own is very important[21]. In this study, L2 and L3 have a certain degree of resistance to acid and bile salt, but in the bile salt concentration $0.2 \%$, the growth of $L 2$ was inhibited. At the same time, although L1 and L5 have a certain degree of resistance to low the bile salt concentration, but didn't grow under $\mathrm{pH} 3.5$; the growth of L4, L6 and L7 were inhibited in low acid and bile salts. Those suggest that strains of acid and bile salt resistant properties are inconsistencies. In addition, all Lactobacillus strains inhibit the growth and adhesion of $H$. pylori in vitro, combined with acid and bile salt resistance, which shows that Lactobacillus has an inhibition effect for $H$. pylori, but it doesn't adapt to the complex stomach environment, which will also be affected to against the infection and inflammation of $H$. pylori in human gastric. It also suggests that the importance of acid and bile salt resistant properties in screening of Lactobacillus as a probiotics agent.

In order to verify the anti-inflammatory effect of Lactobacilli in vivo, we chose the gnotobiotic Kunming mice model. Through establish the mono- and di-associated gnotobiotic models, it clearly revealed the interaction between $H$. pylori and Lactobacillus in vivo. The colonization amount of H. pylori in LHG and HLG are significantly lower than that in HG, which suggest that $L$. crispatus play a role in reducing the engraftment of $H$. pylori in mice. At the same time, the better inhibitor effect that $L$. crispatus inoculated 
after $H$. pylori than L. crispatus inoculated before H. pylori in vitro and in vivo, is helpful for developing $L$. crispatus as probiotics to treat $H$. pylori infections. In addition, the amount of colonization of Lactobacillus is $1.12 \times 10^{6}$ copies/g or more in LHG and HLG, it is consistent with the reports that the colonization amount of Lactobacillus must be more than $1.00 \times 10^{6} \mathrm{CFU} / \mathrm{mL}$ which can play a role of probiotics[24].

In order to study the anti-inflammatory effect of Lactobacilli in gnotobiotic Kunming mice, we detected MPO and histopathology to evaluate the gastritis of stomach tissues. Myeloperoxidase(MPO), which is an oxidative enzyme present in phagocytes, is an essential part of the inflammatory regulation[25]. In some reports, the activity of MPO in mucosal biopsy specimens from patients with $H$. pylori infection is elevated[ 26, 27]. At the same time, H. pylori density were correlated with MPO level in gastric antral mucosa, the H. pylori water extract also increases the secretion of MPO from human neutrophils[28]. Unfortunately, MPO can directly promotes oxidative injury of host tissues at sites of inflammation and induce the expression of IL-1 and TNF-a which can reduce the secretion of stomach acid, and benefit the survival and infection of $H$. pylori 29]. So by testing the MPO levels of organization, we confirmed the inflammation was sig7nificantly lower in LHG and HLG than HG. At the same time the results of histopathology for each groups was consistent with that of MPO. These results clearly demonstrated that the inflammation was significantly reduced by L. crispatus in LHG and HLG.

\section{Conclusions}

In conclusion, six stomach-derived Lactobacillus have resistance to H. pylori, but only L. crispatus has resistance to low acid and high bile salts environment. Through the gnotobiotic Kunming mice model, we further verify the resistance of $L$. crispatus for inhibiting the growth and inflammation $H$. pylori caused in vivo. It is steps closer to clinical potential agents for develop L. crispatus.

\section{Material And Methods}

\section{Bacterial strains and culture conditions}

Six Lactobacillus strains were isolated from the gastric mucosa of 21 healthy volunteers who received gastroscope inspection at Chongqing Southwest Hospital, Chongqing, China. These strains are Lactobacillus oris (L1, L2), Lactobacillus crispatus (L3), Lactobacillus salivarius (L4), Lactobacillus gasseri (L5), Lactobacillus delbrueckii (L6). The standard strain is Lactobacillus acidophilus ATCC4356 (L7). They were cultured in Man-Rogosa-Sharpe (MRS) broth (BD, Shanghai, China), and incubated for 2 days at $37^{\circ} \mathrm{C}$ under $87 \% \mathrm{~N}_{2}, 5 \% \mathrm{O}_{2}$ and $8 \% \mathrm{CO}_{2}$ in three gas incubators (Thermo Scientific, Shanghai, China). After harvesting, the bacterial suspensions were prepared at a concentration of $1.0 \times 10^{9} \mathrm{CFU} / \mathrm{mL}$.

The H. pylori strain M13, which was derived from a Chinese clinical isolate and adapted to colonize the gastric mucous layer (GML) of mice [ 30]. Itwas recovered and cultivated on Skirrow's medium, and then inoculated in brain heart infusion broth supplemented with $5 \%$ foetal bovine serum and $1 \%$ glucose with 
shaking at $220 \mathrm{rpm}$ and $37^{\circ} \mathrm{C}$ under $87 \% \mathrm{~N}_{2}, 5 \% \mathrm{O}_{2}$ and $8 \% \mathrm{CO}_{2}$ in three gas incubators. After harvesting, the concentration of bacteria was regulated to $1.0 \times 10^{9} \mathrm{CFU} / \mathrm{mL}$.

\section{Acid and bile salt resistance of Lactobacillus strains in vitro}

For the acid resistance experiment, the MRS broth's pH value was adjusted to $2.5,3.0,3.5,4.0,4.5$, they were shaked at $220 \mathrm{rpm}$ and $37^{\circ} \mathrm{C}$ for $4 \mathrm{~h}$. In the bile salt resistance experiment, the bile salt concentration of MRS broth is $0.05 \%, 0.1 \%$ and $0.2 \%$, the medium were shaked at $220 \mathrm{rpm}$ and $37^{\circ} \mathrm{C}$ for $4 \mathrm{~h}$, $8 \mathrm{~h}$ and $12 \mathrm{~h}$, respectively. All the initial concentration is $1 \times 10^{8} \mathrm{CFU} / \mathrm{mL}$, the total volume is $20 \mathrm{~mL}$. Then the bacterium solution were centrifuged and then resuspended in $1 \mathrm{~mL}$, each of them was added to 96 -well plates, $200 \mu \mathrm{L}$ per well for two wells, MRS medium as blank control. All the wells tested the value of OD600nm by iMark $^{\text {TM }}$ Microplate Absorbance Reader (BioRad, Hercules, USA).

\section{Inhibition and adhesion of $H$. pylori in vitro}

According to Oxford cup method[ 31 ], The concentration of H. pylori and Lactobacillus strains suspensions was separately regulated to $1.0 \times 10^{7}$ and $1.0 \times 10^{8} \mathrm{CFU} / \mathrm{mL}$. $200 \mu \mathrm{L}$ of $H$. pylori were plated on Skirrow's medium evenly, and waiting for no obvious water droplets, the sterile Oxford cup (Lu Si Precision Instrument, Shanghai, China) was placed inside the tablet for equidistant, $240 \mu \mathrm{L}$ of Lactobacillus strains suspensions were added to the Oxford cup, MRS broth as negative control, and the agar plates were incubated for $48 \mathrm{~h}$ at $37^{\circ} \mathrm{C}$ under $87 \% \mathrm{~N}_{2}, 5 \% \mathrm{O}_{2}$ and $8 \% \mathrm{CO}_{2}$ in three gas incubators. Then measure the size of inhibitory zone diameters (IZD).

For the adhesion assay, the experiment were divided into three groups: the control group, the H. pylori M13 were inoculated in microtiter plates and incubated for 2h; the H-L group, the H. pylori M13 were inoculated in microtiter plates and incubated for 60 minutes, then the Lactobacillus strains were added, followed cultivation for $1 \mathrm{~h}$; the L-H group, the Lactobacillus strains were added to wells first, and inoculated the $H$. pylori M13 in microtiter plates later on, then cultivated for $1 \mathrm{~h}$, respectively. In these groups, gastric mucosal epithelial cells (GES-1) were firstly grown on microtiter plates to form a confluent monolayer after 1 day of culturing[ 32 ]. The microtiter plates were washed three times with normal saline, then the H. pylori and Lactobacillus strains suspensions $(100 \mu \mathrm{L})$ was added to each well, their concentration were $1.0 \times 10^{7}$ and $1.0 \times 10^{8} \mathrm{CFU} / \mathrm{mL}$, separately. After 120 minutes' incubation, nonadherent bacteria were washed off by normal saline for three times. The level of adherent bacteria was estimated by the urease assay[ 33 ], 100 $\mathrm{L}$ of urease test solution ( $7 \mathrm{mM}$ phosphate buffer $\mathrm{pH} 6.8$, $110 \mathrm{mM}$ urea, $10 \mathrm{mg} / \mathrm{L}$ phenol red) was added into each well of microtiter plate, after a reaction time of 30 min at $37^{\circ} \mathrm{C}$, absorbance values at $540 \mathrm{~nm}$ line were recorded with a iMark ${ }^{\mathrm{TM}}$ Microplate Absorbance Reader. The adhesion level was calculated by the absorbance value of the sample divided by the absorbance value of control group. 


\section{Mono- and di-associated gnotobiotic Kunming mice models}

Six-week-old male gnotobiotic Kunming mice (weight, 20 $\pm 1 \mathrm{~g}$ ) were purchased from Department of Laboratory Animal Science, College of Basic Medical Sciences, the Third Military Medical University (Chongqing, China) and were maintained under standard laboratory conditions (constant temperature, 23 $\pm 2{ }^{\circ} \mathrm{C}$; relative humidity, $55 \pm 5 \%$; 12 -h light: 12 -h dark cycle) with free access to an autoclaved pellet diet and sterile water. After a 1-week equilibration period, these mice were used in the experiments. All animal experiments were approved by the Animal Ethical and Experimental Committee of Third Military Medical University.

The mice were divided randomizedly into four groups (eight animals per group): H. pylori M13 gnotobiotic group (HG), which received only $0.4 \mathrm{~mL}$ of $H$. pylori suspension orally by gavage; L. crispatus gnotobiotic group (LG), which was orally given $0.4 \mathrm{~mL}$ L. crispatus, L. crispatus and H. pylori M13gnotobiotic group (LHG), which were successively given oral administration of L. crispatus $(0.4 \mathrm{~mL})$ and H. pylori $(0.4 \mathrm{~mL})$; $H$. pylori M13and L. crispatus gnotobiotic group (HLG), which were successively given oral administration of H. pylori $(0.4 \mathrm{~mL})$ and L. crispatus $(0.4 \mathrm{~mL})$. Both of the concentration of H. pylori and L. crispatus is $1.0 \times 10^{9} \mathrm{CFU} / \mathrm{mL}$, they were inoculated twice a day for two days. In LHG and HLG, after four weeks the $L$. crispatus or H. pylori M13 were successively given oral administration, H. pylori M13 or L. crispatus linewere given oral administration again. All mice were housed for 8 weeks under above described conditions.

\section{Detection of $H$. pylori and L. crispatus}

Infection with $\mathrm{H}$. pylori was assessed using bacterial culture, urease test and PCR. Viable colonies for each stomach were identified as $H$. pylori on the agar plates, which were positive for mice. Both the urease test and PCR were positive, which were defined as positive for H. pylori. According to Bergey's Manual of Determinative Bacteriology, L. crispatus were identified by colony morphology, gram staining and microscopic examination. The viable colonies were white colony on MRS agars, gram positive, rodshaped under microscope, which were positive for L. crispatus.

Eight weeks after inoculation, mice were sacrificed by cervical dislocation. The stomachs were removed from the mice and cut into four parts. One part of the stomach was serial plated on Skirrow's medium and MRS agars, separately. The Skirrow agar plates were incubated for 2 days at $37^{\circ} \mathrm{C}$ under $\mathrm{N}_{2} 87 \%, 5 \% \mathrm{O}_{2}$ and $8 \% \mathrm{CO}_{2}$ in three gas incubators; the MRS agars were incubated for $24 \mathrm{~h}$ under the same conditions. One part of the stomach was homogenised with normal saline, the mixture was identified using the urease test. In addition, the mixture was also centrifuged for $5 \mathrm{~min}$ at $13000 \times \mathrm{g}$, and the precipitate was collected for PCR and qRT-PCR. PCR and qRT-PCR analysis of the samples was performed using a previously reported method [ 34 ]. The DNA was isolated from the precipitate using the Microbial Genomic DNA Extraction Kit [35]. The PCR primers used to amplify the ureC ( $\mathrm{glmM}$ ) gene of H. pylori were F: 5'AAGCTTTTAGGGGTGTTAGGGGTTT-3' and R: 5'-AAGCTTACTTTCTAACACTAACGC-3'. The assay was run 
on an S-1000 (BioRad). After a denaturation step at $94^{\circ} \mathrm{C}$ for $3 \mathrm{~min} ; 35$ cycles were performed for PCR amplification, where the cycle parameters were $94^{\circ} \mathrm{C}$ for $45 \mathrm{sec}, 55^{\circ} \mathrm{C}$, for $30 \mathrm{sec}, 72^{\circ} \mathrm{C}$ for $30 \mathrm{sec}$;

followed by an extension step at $72^{\circ} \mathrm{C}$ for $5 \mathrm{~min}$. The PCR product was separated by electrophoresis with a $2 \%$ gel containing ethidium bromide and visualised with a UV light source.

The colonisation of $H$. pylori and L.crispatus was quantified by amplifying the 16S rRNA. For 16S rRNA, the primers used were $H$. pylori-F: 5'-TTTGTTAGAGAAGATAATGACGGTATCTAAC-3' and R: 5'-

CATAGGATTTCACACCTGACTGACTATC-3'; L. crispatus-F: 5'-TGGAAACAGATGCTAATACCG-3' and R: 5'CGTCCATTGTGGTAGATTCCCT-3'; the TaqMan probe was $H$. pylori-P: 5'-FAM-CGTGCCAGCAGCCGCGGTTAMRA-3' and L. crispatus-P: 5'-FAM-CTGAGACACGGCCCAAACTCCTACGG-ECLIPSE-3'. The assay was run on a CFXTM Real-Time System (BioRad). After a denaturation step at $95^{\circ} \mathrm{C}$ for 2 min, 40 cycles were performed for PCR amplification. The cycle parameters were $95^{\circ} \mathrm{C}$ for $5 \mathrm{sec}$ and $60^{\circ} \mathrm{C}$ for $30 \mathrm{sec}$.

\section{Determination of gastric tissue MPO level}

One part of the stomach tissue was homogenised with normal saline, the mixture were also centrifuged at $20000 \times \mathrm{g}$ for $15 \mathrm{~min}$ at $4^{\circ} \mathrm{C}$, then the supernatant was collected. MPO level was measured using a Mouse MPO Elisa Kit (R\&D Systems, Minneapolis, USA).

\section{Histopathology analysis of gastric tissue by H\&E staining}

One part of the stomach tissue were fixed by standard methods for histopathology ( $10 \%$ formaldehyde, $0.2 \mathrm{M}$ sodium phosphate buffer, $\mathrm{pH} 7.4$ ), fixed tissue was embedded in paraffin, sectioned, and stained with hematoxylin and eosin (Absin, Shanghai, China) for evaluation of gastric inflammation. Inflammation was scored using the updated Sydney System[36]. The pathologic characteristics were scored for the degree of neutrophil and mononuclear cell infiltration in the gastric mucosa: score 0 , normal; score 1, mild; score 2, moderate; score 3, marked inflammatory changes.

\section{Statistical analysis}

The data from three independent experiments and are expressed as means \pm standard deviations (SD). The statistical analyses were performed using IBM SPSS Statistics version 19 software (IBM China Inc., Beijing, China), for statistical comparisons, the independent-sample t test and $\chi^{2}$ test or Fisher's exact test were performed, statistically significant differences between groups were defined as a $P$ value of $<0.05$.

\section{List Of Abbreviations}

Helicobacter pylori (H. pylori), gastric mucous layer (GML), H. pylori M13 gnotobiotic group (HG), L. crispatus gnotobiotic group (LG), L. crispatus and H. pylori M13gnotobiotic group (LHG), H. pylori M13and L. crispatus gnotobiotic group (HLG). 


\section{Declarations}

\section{Ethics approval and consent to participate}

This study was approved by the Ethics Committee of the Southwest Hospital of Third Military Medical University. Written informed consent was obtained from all individual participants included in the study. The breeding of animals and protocol of animal experiment were approved by the Animal Ethics Committee of Third Military Medical University, Chongqing, China.

\section{Consent for publication}

Not applicable

\section{Availability of data and materials}

All data generated or analysed during this study are included in this published article.

\section{Competing interests}

The authors declare that they have no competing interests.

\section{Funding}

This study was funded by NSFC (National Natural Science Foundation of China) item (No. 31070445, 81370906). Dr. Guo is the recipient of these fundings, and he designed the study and revised the manuscript.

\section{Authors' contributions}

GG and YL designed the study. NW and FM contributed equally to this work, and carried out the experimental work together. NW drafted the manuscript. WH and HK provided technical support. YS and ZY participated in its design. QZ coordinated the study. All authors read and approved the final manuscript.

\section{Acknowledgements}

We thank the Digestive Department of Chongqing Southwest Hospital for providing the six clinical Lactobacillus strains.

\section{References}

1. Inoue I, Mukoubayashi C, Yoshimura N, Niwa T, Deguchi H, Watanabe M, Enomoto S, Maekita T, Ueda K, Iguchi M: Elevated risk of colorectal adenoma with Helicobacter pylori-related chronic gastritis: A population-based case-control study. Int J Cancer 2011, 129(11):2704-2711. 
2. Kim JM, Kim JS, Kim YJ, Oh YK, Kim IY, Chee YJ, Han JS, Jung HC: Conjugated linoleic acids produced by Lactobacillus dissociates IKK-y and Hsp90 complex in Helicobacter pylori-infected gastric epithelial cells. Lab Invest 2008, 88(5):541-552.

3. Lofgren JL, Whary MT, Ge Z, Muthupalani S, Taylor NS, Mobley M, Potter A, Varro A, Eibach D, Suerbaum S: Lack of Commensal Flora in Helicobacter pylori-Infected INS-GAS Mice Reduces Gastritis and Delays Intraepithelial Neoplasia. Gastroenterology 2011, 140(1):210-220.

4. Malfertheiner P, Megraud F, O'Morain CA, Atherton J, Axon AT, Bazzoli F, Gensini GF, Gisbert JP, Graham DY, Rokkas T: Management of Helicobacter pylori infection-the Maastricht IV/Florence consensus report. Gut 2012, 61(5):646-664.

5. Liou JM, Chen CC, Chen MJ, Chen C-C, Chang C-Y, Fang Y-J, Lee JY, Hsu S-J, Luo J-C, Chang W-H: Sequential versus triple therapy for the first-line treatment of Helicobacter pylori: a multicentre, open-label, randomised trial. Lancet 2013, 381(9862):205-213.

6. Meyer JM, Silliman NP, Wang WJ, Siepman NY, Sugg JE, Morris D, Zhang J, Bhattacharyya H, King EC, Hopkins RJ: Risk factors for Helicobacter pylori resistance in the United States: the surveillance of $H$. pylori antimicrobial resistance partnership (SHARP) study, 1993-1999. Ann intern med 2002, 136(1):1324.

7. Zhou QL, Li KM, Jun X, Bo L: Role and functions of beneficial microorganisms in sustainable aquaculture. Bioresource Technol 2009, 100(16):3780-3786.

8. Linsalata M, Russo F, Berloco P, Caruso ML, Matteo GD, Cifone MG, Simone CD, lerardi E, Leo AD: The Influence of Lactobacillus brevis on Ornithine Decarboxylase Activity and Polyamine Profiles in Helicobacter pylori-Infected Gastric Mucosa. Helicobacter 2004, 9(2):165-172.

9. Chen XH, Liu XM, Tian FW, Zhang Q, Zhang Hp, Zhang H, Chen W: Antagonistic activities of lactobacilli against Helicobacter pylori growth and infection in human gastric epithelial cells. J Food Sci 2012, 77(1):M9-M14.

10. Sunanliganon C, Thong-Ngam D, Tumwasorn S, Klaikeaw N: Lactobacillus plantarum B7 inhibits Helicobacter pylori growth and attenuates gastric inflammation. World J Gastroentero 2012, 18(20):24722480 .

11. Sakamoto I, Igarashi M, Kimura K, Takagi A, Miwa T, Koga Y: Suppressive effect of Lactobacillus gasseri OLL 2716 (LG21) on Helicobacter pylori infection in humans. J Antimicrob Chemoth 2001, 47(5):709-710.

12. Zaman C, Osaki T, Hanawa T, Yonezawa H, Kurata S, Kamiya S: Analysis of the microflora in the stomach of Mongolian gerbils infected with Helicobacter pylori. J Gastroen Hepato/2010, 25(s1):S11S14. 
13. Thiraworawong T, Spinler JK, Werawatganon D, Klaikeaw N, Venable SF, Versalovic J, Tumwasorn S: Anti-inflammatory Properties of Gastric-derived Lactobacillus plantarum XB7 in the Context of Helicobacter pylori Infection. Helicobacter 2014, 19:144-155.

14. Reddy BS: Prevention of colon cancer by pre-and probiotics: evidence from laboratory studies. Brit J Nutr 1998, 80(4):S219-223.

15. Lin DC: Probiotics as functional foods. Nutr Clin Pract 2003, 18(6):497-506.

16. Kim MN, Kim N, Lee SH, Park YS, Hwang JH, Kim JW, Jeong SH, Lee DH, Kim JS, Jung HC: The Effects of Probiotics on PPI-Triple Therapy for Helicobacter pylori Eradication. Helicobacter 2008, 13(4):261-268.

17. Kamiji MM, De Oliveira RB: Non-antibiotic therapies for Helicobacter pylori infection. Eur J Gastroen Hepat 2005, 17(9):973-981.

18. Gilliland S, Staley T, Bush L: Importance of Bile Tolerance of Lactobacillus acidophilus Used as a Dietary Adjunct. J Dairy Sci 1984, 67(12):3045-3051.

19. Hove $H, N ø r g a a r d ~ H$, Mortensen PB: Lactic acid bacteria and the human gastrointestinal tract. Eur J Clin Nutr 1999, 53(5):339-350.

20. Cotter PD, Hill C: Surviving the acid test: responses of gram-positive bacteria to low $\mathrm{pH}$. Microbiol Mol Biol R 2003, 67(3):429-453.

21. Prasad J, Gill H, Smart J, Gopal PK: Selection and Characterisation of Lactobacillus and Bifidobacterium Strains for Use as Probiotics. Int Dair J 1998, 8(12):993-1002.

22. Silva M, Jacobus N, Deneke C, Gorbach S: Antimicrobial substance from a human Lactobacillus strain. Antimicrob Agents Ch 1987, 31(8):1231-1233.

23. Engstrand L, Lindberg M: Helicobacter pylori and the gastric microbiota. Best Pract Res Cl Ga 2013, 27(1):39-45.

24. Hungin APS, Mulligan C, Pot B, Whorwell P, Agreus L, Fracasso P, Lionis C, Mendive J, de Foy JMP, Rubin $\mathrm{G}$ et al: Systematic review: probiotics in the management of lower gastrointestinal symptoms in clinical practice - an evidence-based international guide. Aliment Pharm Therap 2013, 38(8):864-886.

25. Winterbourn CC, Vissers MC, Kettle AJ: Myeloperoxidase. Curr Opin Hemato/ 2000, 7(1):53-58.

26. Nøorgaard A, Andersen L, Nielsen H: Neutrophil degranulation by Helicobacter pylori proteins. Gut 1995, 36(3):354-357.

27. Suzuki H, Mori M, Seto K, Kai A, Kawaguchi C, Suzuki M, Suematsu M, Yoneta T, Miura S, Ishii H: Helicobacter pylori-associated gastric pro-and antioxidant formation in Mongolian gerbils. Free Radical 
Bio Med 1999, 26(5):679-684.

28. Kim JS, Jung HC, Kim JM, Song IS, Kim CY: Helicobacter pylori water-soluble surface proteins activate human neutrophils and up-regulate expression of CXC chemokines. Digest Dis Sci 2000, 45(1):83-92.

29. Nazligul Y, Aslan M, Horoz M, Celik Y, Dulger AC, Celik H, Erel O: The effect on serum myeloperoxidase activity and oxidative status of eradication treatment in patients Helicobacter pylori infected. Clin Biochem 2011, 44(8):647-649.

30. Liu KY, Du FC, Fu Q, Zhang WJ, Sun HW, Zhang Y, Gan LL, Yue ZY, Zou QM, Guo G: Efficacy and pharmacological mechanism of pronase-enhanced low-dose antibiotics for Helicobacter pylori eradication. Antimicrob Agents Ch 2014, 58(6):3348-3353.

31. Sherwood MB, de Beer EJ: Discrepancy in analysis of penicillin in blood by the Oxford cup method as revealed by the paper disc technique. Science 1947, 105:414.

32. Rokka S, Myllykangas S, Joutsjoki V: Effect of Specific Colostral Antibodies and Selected Lactobacilli on the Adhesion of Helicobacter pylori on AGS Cells and the Helicobacter-Induced IL-8 Production. Scand $J$ Immunol 2008, 68(3):280-286.

33. Shmuely H, Burger O, Neeman I, Yahav J, Samra Z, Niv Y, Sharon N, Weiss E, Athamna A, Tabak M: Susceptibility of Helicobacter pylori isolates to the antiadhesion activity of a high-molecular-weight constituent of cranberry. Diagn Micr Infec Dis 2004, 50(4):231-235.

34. Lu JJ, Perng CL, Shyu RY, Chen CH, Lou Q, Chong SK, Lee CH: Comparison of five PCR methods for detection of Helicobacter pylori DNA in gastric tissues. J Clin Microbiol 1999, 37(3):772-774.

35. Guo G, Jia KR, Shi Y, Liu XF, Liu KY, Qi W, Guo Y, Zhang WJ, Wang T, Xiao B: Psychological stress enhances the colonization of the stomach by Helicobacter pylori in the BALB/c mouse. Stress 2009, 12(6):478-485.

36. Dixon MF, Genta RM, Yardley JH, Correa P: Classification and grading of gastritis: the updated Sydney system. Am J Surg Pathol 1996, 20(10):1161-1181.

\section{Tables}

Table 1 Inhibition zone diameters ( $\mathrm{mm}$ ) of all Lactobacillus suspensions

\begin{tabular}{lllllllll} 
strain & L1 & L2 & L3 & L4 & L5 & L6 & L7 & MRS \\
\hline $\begin{array}{l}\text { IZM } \\
(\mathrm{mm})\end{array}$ & $15.7 \pm 0.3$ & $17.0 \pm 0.1$ & $24.2 \pm 0.1$ & $15.0 \pm 0.2$ & $14.2 \pm 0.1$ & $14.1 \pm 0.1$ & $13.0 \pm 0.1$ & $8.0 \pm 0.1$ \\
$\begin{array}{l}p \\
\text { value } \\
\text { a }\end{array}$ & 0.000 & 0.000 & & 0.000 & 0.000 & 0.000 & 0.000 & \\
& & & & & & & &
\end{tabular}


a L3 versus other strains.

Table 2 The adhesion rate of $H$. pylori in the presence of Lactobacillus

\begin{tabular}{llll} 
& L-H group(\%) & H-L group(\%) & $p$ value \\
\hline L1 & 54.0 & 49.6 & $<0.01 \mathrm{a}, \mathrm{b}$ \\
\hline L2 & 56.3 & 52.2 & $<0.01 \mathrm{a}, \mathrm{b}$ \\
\hline L3 & 51.2 & 41.3 & $<0.01 \mathrm{c}$ \\
\hline L4 & 61.2 & 53.6 & $<0.01 \mathrm{a}, \mathrm{b}$ \\
\hline L5 & 62.4 & 55.4 & $<0.01 \mathrm{a}, \mathrm{b}$ \\
\hline L6 & 66.8 & 56.9 & $<0.01 \mathrm{a}, \mathrm{b}$ \\
\hline L7 & 66.0 & 52.3 & $<0.01 \mathrm{a}, \mathrm{b}$
\end{tabular}

a L3 versus other strains in L-H group.

b L3 versus other strains in $\mathrm{H}-\mathrm{L}$ group.

c L3 in L-H group versus that in H-L group.

Table 3 The colonization amount of $H$. pylori and L. crispatus in different gnotobiotic Kunming mice.

\begin{tabular}{llll}
$\begin{array}{l}\text { Group } \\
(\mathrm{n}=8)\end{array}$ & qRT-PCR (copies/g) & p value \\
& & & \\
& H. pylori & L. crispatus & \\
& & & \\
\hline HG & $2.008 \mathrm{E}+07 \pm 7.27 \mathrm{E}+06$ & - & \\
\hline LG & - & $1.650 \mathrm{E}+08 \pm 4.26 \mathrm{E}+07$ & \\
\hline LHG & $3.85 \mathrm{E}+06 \pm 2.53 \mathrm{E}+06$ & $1.12 \mathrm{E}+06 \pm 8.9 \mathrm{E}+05$ & $<0.01 \mathrm{a}, \mathrm{b}$ \\
\hline HLG & $1.35 \mathrm{E}+06 \pm 6.5 \mathrm{E}+05$ & $5.32 \mathrm{E}+06 \pm 2.14 \mathrm{E}+06$ & $<0.01 \mathrm{a}$
\end{tabular}

a HG versus LHG and HLG about the colonization amount of $H$. pylori.

b HLG versus LHG about the colonization amount of L. crispatus.

Table 4 Summary of gastric inflammation scores in all groups 
Group Gastric inflammation

$p$ value

\begin{tabular}{llllll}
$(n=8)$ & & 1 & 2 & 3 & \\
\hline & 0 & - & - & - & \\
\hline LG & 8 & 6 & 2 & - & \\
\hline$H G$ & - & 4 & - & - & $0.010 a$ \\
\hline LHG & 4 & 3 & - & - & $0.003 a$
\end{tabular}

a $H G$ versus $L H G$ and $H L G$.

Figures

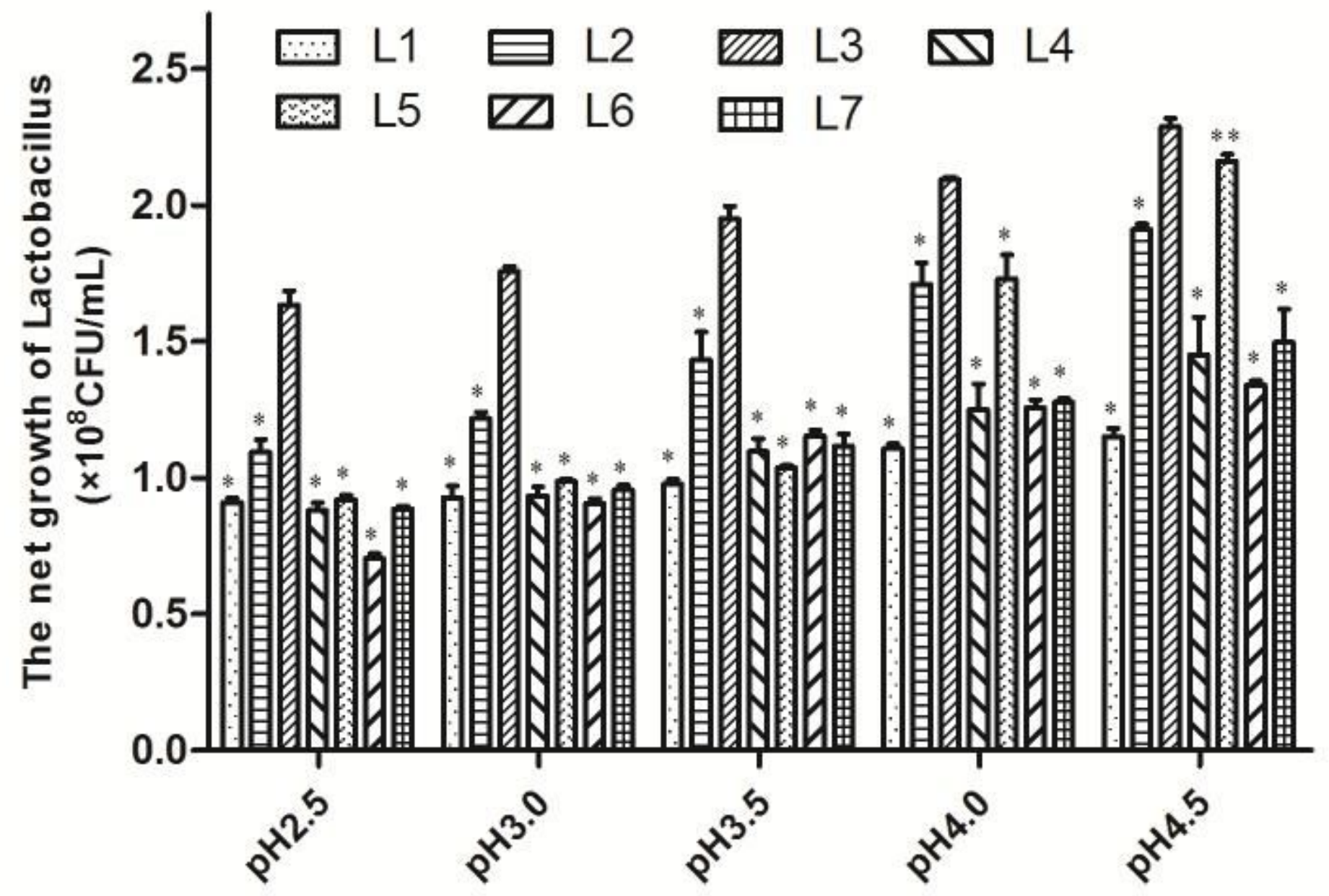

Figure 1 
Comparison of net growth of seven Lactobacillus strains in different pH MRS broth after four hours incubation. The initial concentration of cultivation is $1 \times 108 \mathrm{CFU} / \mathrm{mL}$, the results are expressed as the mean \pm SD. The net growth were statistically significant differences in the L3 compared with the other strains at the same $\mathrm{pH}\left({ }^{\star} \mathrm{p}<0.01,{ }^{\star *} \mathrm{p}<0.05\right)$.

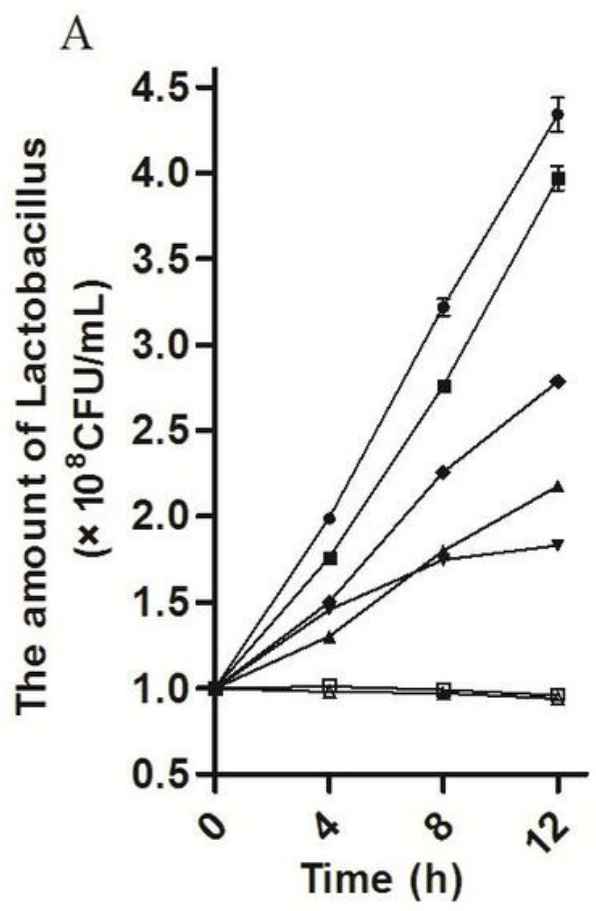

$\mathrm{B}$

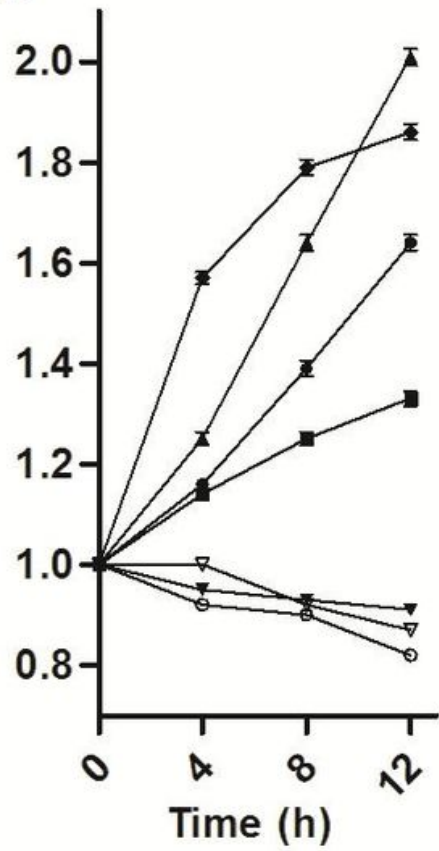

C

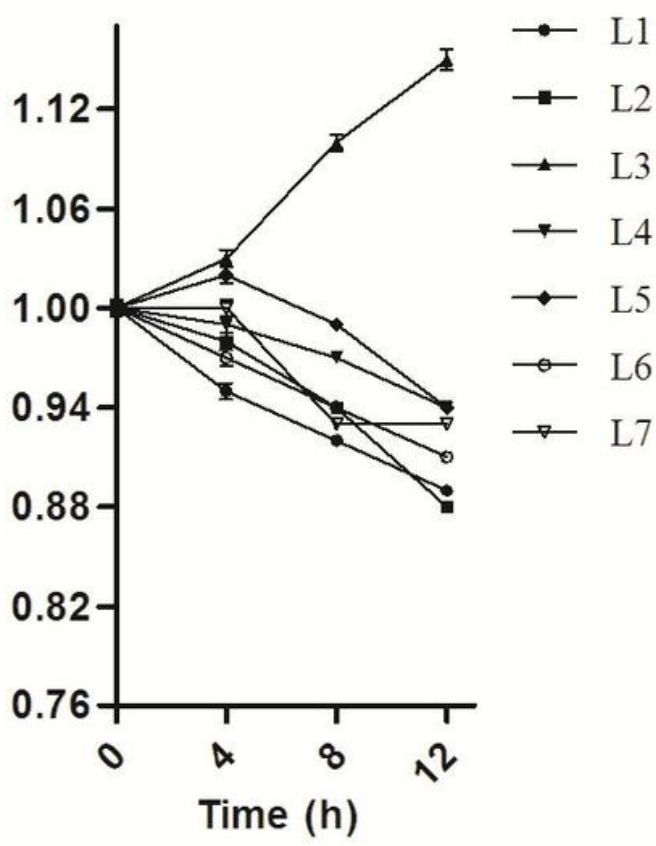

Figure 2

The growth rate of strains at different concentrations of bile salts. (A) The bile salt concentration of MRS broth is $0.05 \%$. (B) The bile salt concentration of MRS broth is $0.1 \%$. (C) The bile salt concentration of MRS broth is $0.2 \%$. All the initial concentration of cultivation is $1 \times 108 \mathrm{CFU} / \mathrm{mL}$, the results are expressed as the mean \pm SD. 


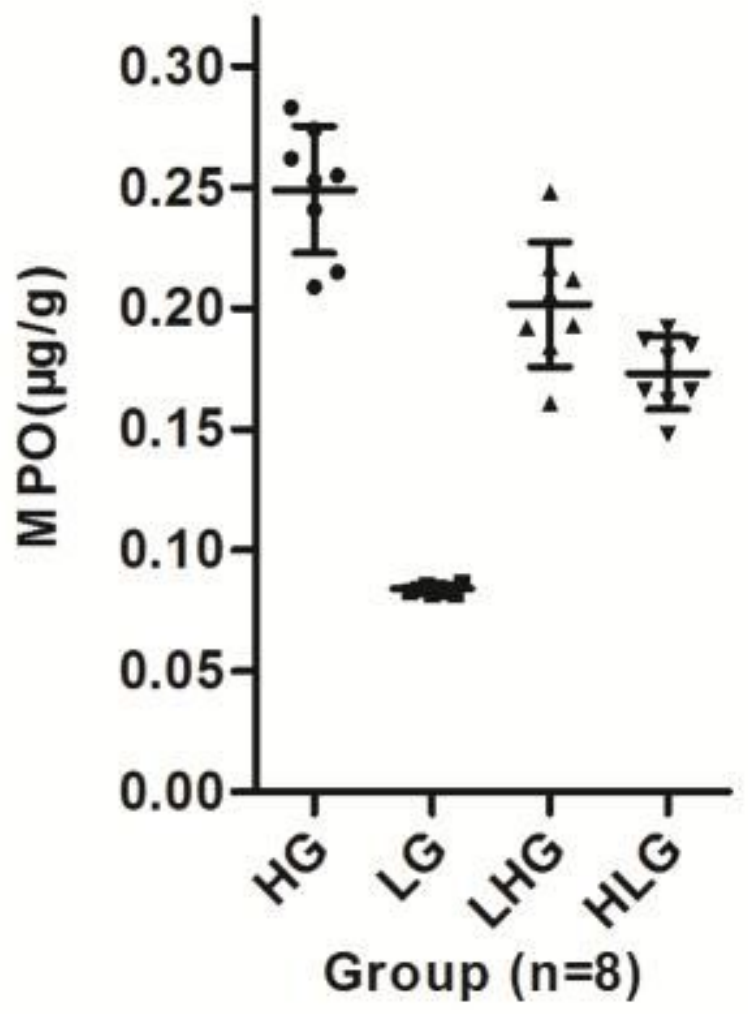

Figure 3

MPO content of gastric tissue in different gnotibiotic Kunming mice. Medians (long horizontal lines) and SD (error bars) are shown. The level of MPO had significant difference between any two of those four groups $(p<0.05)$. 

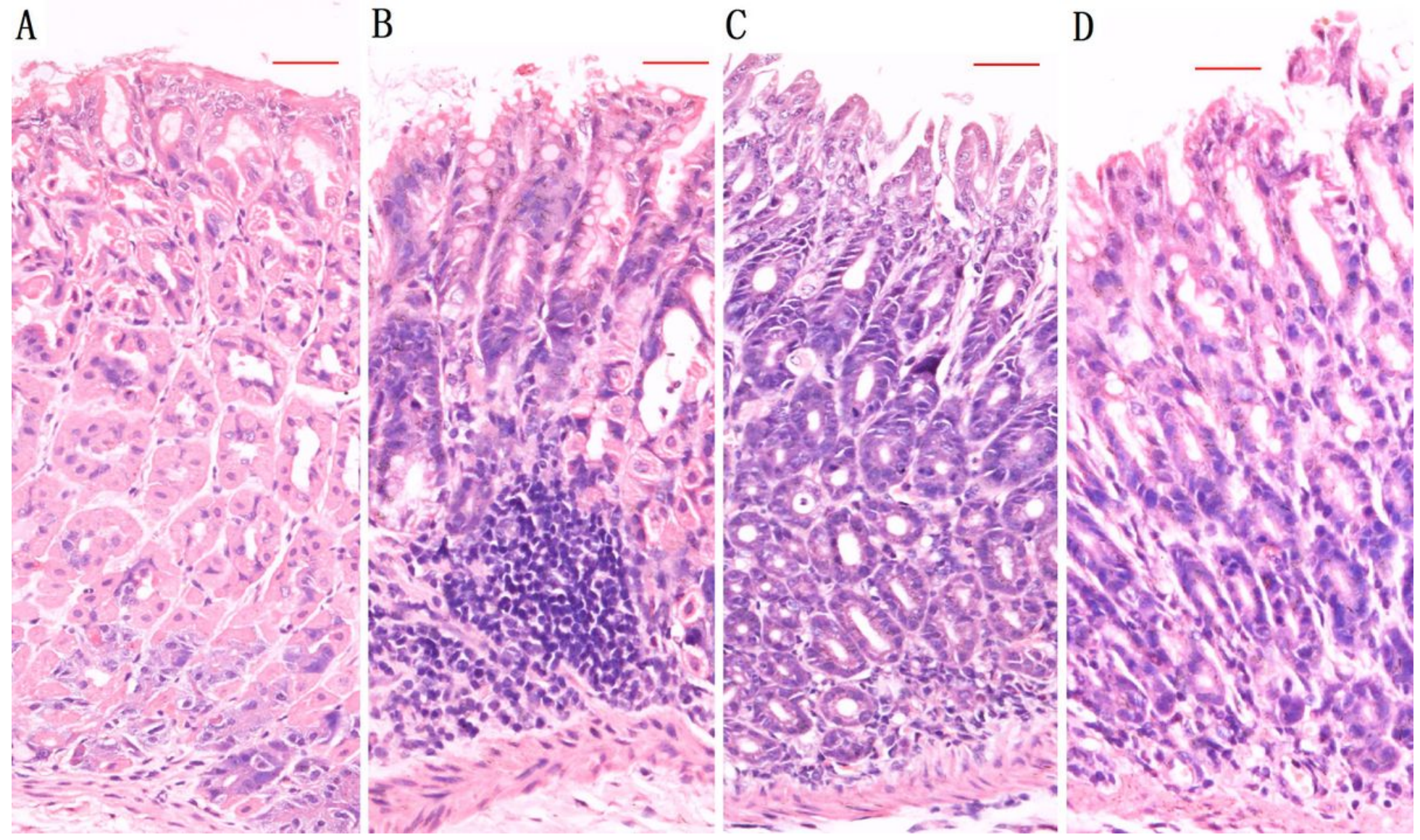

Figure 4

Histopathological examination of stomachs of gnotobiotic mice by H\&E stained. a LG showed no gastric inflammation; b HG showed a amount of neutrophil and mononuclear cell infiltration and the destroyed glands structure (arrows); c, d LHG and HLG showed small number of neutrophil and mononuclear cell infiltration (arrows). Original magnification, $\times 200$; bars $=25 \mu \mathrm{m}$.

\section{Supplementary Files}

This is a list of supplementary files associated with this preprint. Click to download.

- NC3RsARRIVEGuidelinesChecklist.PDF 